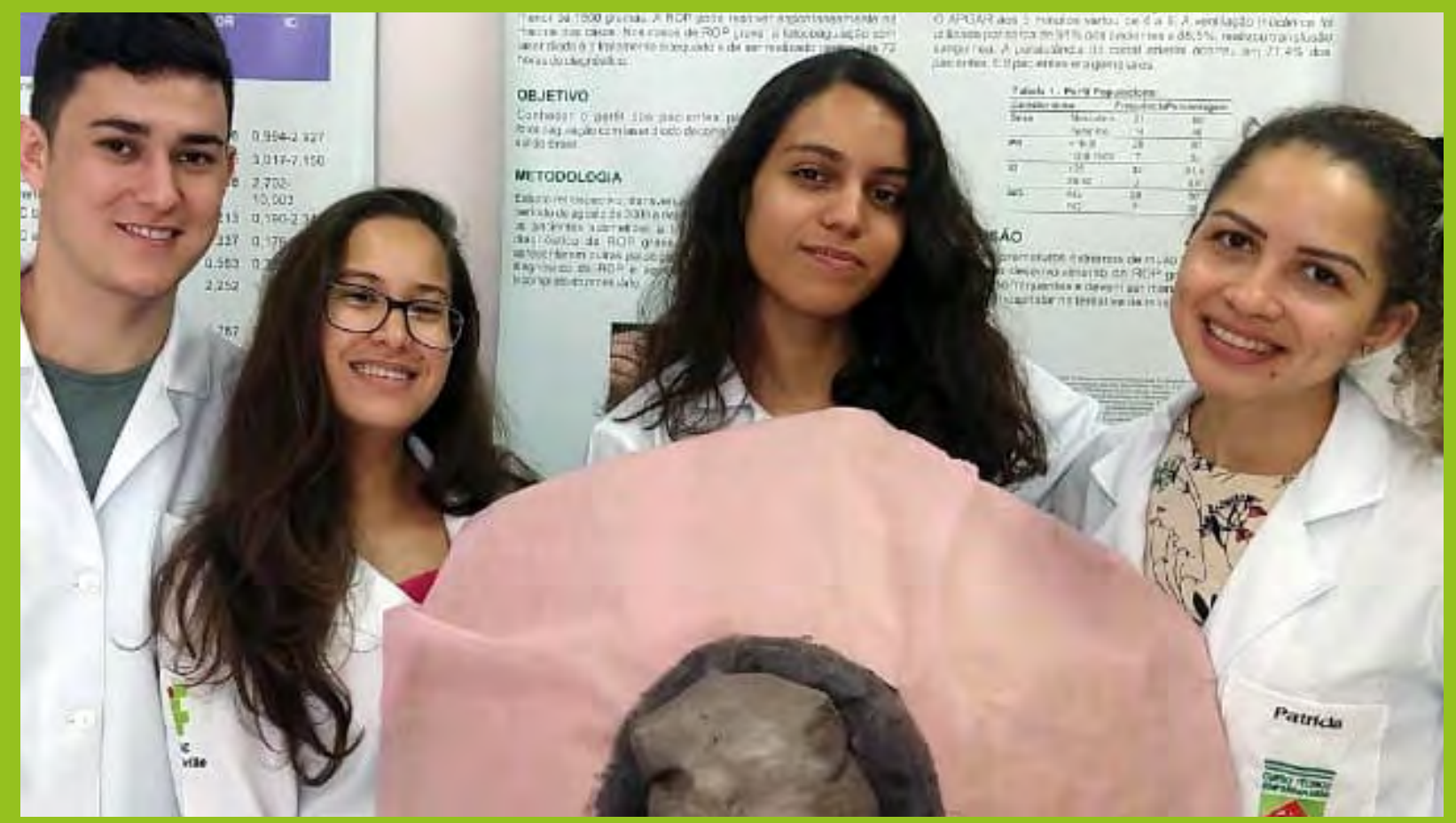

\title{
Promoção do aleitamento materno através da utilização de uma metodologia ativa
}

Patrícia Fernandes Albeirice da Rocha ${ }^{1}$ patricia.albeirice@ifsc.edu.br

\section{Fabiana Calçada de Lamare Leite ${ }^{2}$}

fabianac@ifsc.edu.br

Betina Barbedo Andrade ${ }^{3}$

betina.barbedo@ifsc.edu.br

\section{Bruna Pescador Mendonça ${ }^{4}$ brupescador@gmail.com}

1 Enfermeira. Mestra em Enfermagem pela UFSC. Docente do curso técnico em enfermagem do IFSC.

2 Geógrafa. Doutora em Geografia pela UFPR. Docente do curso superior de tecnologia em gestão de Turismo do IFSC.

3 Enfermeira. Doutora em Saúde e Desenvolvimento pela UFSM. Docente do curso técnico em enfermagem do IFSC.

4 Enfermeira. Doutora em Ciências da Saúde pela UNESC. Docente do curso técnico em enfermagem do IFSC 
Objetivo: Construir o conhecimento de alunos e famílias sobre aleitamento materno através da participação ativa dos indivíduos. MÉTODO: Foi realizada uma ação educativa, com roda de conversa, intermediado pelos alunos do curso técnico em enfermagem, sobre aleitamento materno, priorizando o conhecimento prévio e cultura das gestantes/puérperas e suas famílias. Resultados: Esta metologia auxiliou na construção do conhecimento, através de estudos fortalecendo o aprendizado, onde os estudantes buscaram o conhecimento científico transformando em linguagem simples para o atendimento às famílias. Conclusão: 0 uso de metodologias ativas tornou o estudante protagonista de sua aprendizagem, mostrando-se benéfico tanto para as famílias participantes quanto para os alunos, pois ambos tiveram espaço para diálogo e interação. Palavras-chave: Aleitamento Materno; Promoção da Saúde; Educação em Saúde; Metodologias Ativas

ABSTRACT

Aim: Building the knowledge of students and children about breastfeeding through the active participation of individuals. Method: An educational action was carried out, with a discussion thread, intermediated by students of the nursing technical course, on breastfeeding, prioritizing prior knowledge and culture of pregnant / puerperal women and their families. Results: This methodology assisted in the construction of knowledge, through studies that strengthened learning, where students sought scientific knowledge, transforming them into simple language for the care of families. Conclusion: The use of active methodologies made the student the protagonist of his / her learning, proving to be beneficial both for the participating families and for the students, since both had space for dialogue and interaction.

Keywords: Breastfeeding. Health Promotion. Health Education. Active Methodologies

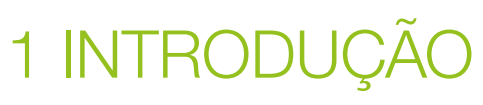

0 ser humano sempre dependeu do leite materno para garantir sua sobrevivência. Porém, ao longo da história da humanidade a amamentação foi fortemente modificada por valores culturais, muitas vezes influenciando negativamente sua prática (CASTILHO; BARROS FILHO, 2010).

0 ato de amamentar está historicamente determinado e condicionado ao seu valor social. Com a Revolução Industrial, a mulher começou a afastar-se desta função: assim como com a crescente participação da mulher no mercado de trabalho, houve a criação de alimentos substitutos, vindo ao encontro de vantagens comerciais e interesses financeiros das indústrias (CASTILHO; BARROS FILHO, 2010).

Atualmente, com os conhecimentos sobre a superioridade em relação à qualidade do leite materno em relação a leites artificiais, foram criadas leis de proteção e incentivo ao aleitamento materno, direito a licença maternidade, regulação de propagandas de produtos que prejudicam a amamentação (BRASIL, 2001; 2002a; 2002b; 2006).

Os benefícios do aleitamento materno já foram documentados e se referem principalmente à boa evolução do crescimento e desenvolvimento infantil, fortalecimento do sistema imunológico, prevenindo principalmente infecções do trato respiratório e otites, alergias, prevenção de obesidade infantil, além de contribuir para a queda da mortalidade infantil em diversos países (OMS, 2007; VICTORA et al., 2016). Também está relacionado a melhores desempenhos em testes de inteligência e maior renda na vida adulta (VICTORA et al., 2015).

Além das vantagens documentadas para o recém-nascido, a mãe também é beneficiada, pois durante o aleitamento prolongado está documentado que há diminuição do risco de diabetes tipo 2, câncer de ovário e câncer de mama, além de auxiliar na recuperação do peso anterior à gestação mais rapidamente (BRASIL, 2013; VICTORA et al., 2016).

0 Brasil está melhorando a assistência à saúde da mulher e do recém-nascido e para isso tem firmado compromissos internos e externos com objetivo de reduzir a morbimortalidade materna e infantil. 0 aumento das taxas de aleitamento materno é uma meta a ser alcançada (BRASIL, 2014).

Todo o processo de gestação, parto e puerpério são muito presentes em nossa cultura, sendo a amamentação um tema mergulhado em questões fortemente culturais, que são passadas de geração para geração, e nos deparamos atualmente com algumas questões culturais que podem ser prejudiciais, como ser considerado moderno oferecer mamadeiras e chupetas e o abandono precoce do aleitamento materno (DEL CASTANHEL, 2016).

Assim, torna-se necessário ouvir as famílias, respeitar sua cultura para compreender o motivo do abandono aleitamento materno, para a partir de então propor uma mudança que seja realmente significativa 
para a família, podendo, então, sugerir mudanças que ressignifiquem a experiência de amamentar. Desta forma, pensar emeducação em saúde é respeitar a individualidade do sujeito, valorizando seus conhecimentos prévios e sua cultura. A abordagem dialógica pode colaborar, então, para o sucesso e mudança nas ações de saúde da pessoa (FREIRE, 2002).

Incentivar a amamentação éimportante pois reduz gastos assistenciais com internações, tratamentos de alergias e doenças respiratórias. Além disso, contribui para o desenvolvimento social e econômico, pois aumenta a inteligência e produtividade dos cidadãos (GARCIA, 2016).

Sabendo que a metodologia ativa de aprendizagem traz a efetiva participação do indivíduo e subsidia a construção do conhecimento do mesmo, foram realizadas rodas de conversa para envolver a mãe e família no cuidado do bebê no quesito amamentação. Para isso, os alunos do curso técnico em enfermagem elaboraram as rodas de conversa e duas professoras mediaram as discussões com as mães e familiares que estiveram no quarto de internação de alto risco ou alojamento conjunto

Assim, o objetivo deste trabalho foi responder se a roda de conversa é favorável para a promoção do aleitamento materno, e se a metodologia ativa contribui para o aprendizado sobre aleitamento materno e ressignificar o conhecimento de alunos e famílias sobre aleitamento materno através da participação ativa dos indivíduos.

\section{METODOLOGIA}

Trata-se de uma pesquisa-ação, aplicada, qualitativa, desenvolvida através de uma atividade de extensão sobre promoção do aleitamento materno.

Inicialmente foi disponibilizado material para estudo sobre aleitamento materno, além do conteúdo já trabalhado anteriormente na disciplina de saúde da mulher (DEL CASTANHEL, 2016).

Durante a preparação para a atividade de educação em saúde, os alunos construíram um protótipo de uma mama gigante (Figura 1), na dimensão de um metro de diâmetro.

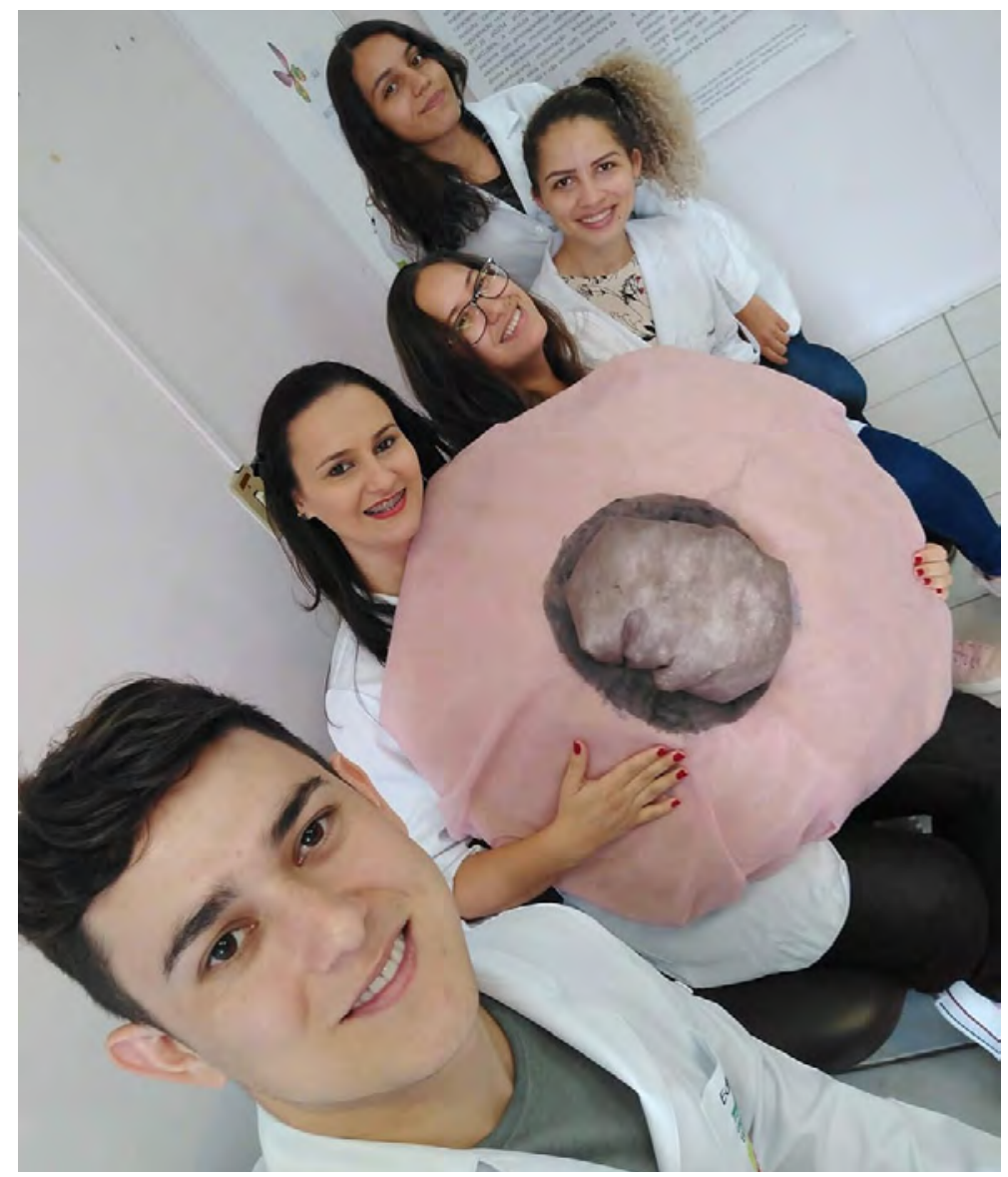

Figura 1: Protótipo de mama.

Fonte: Dados desta pesquisa. 
Durante a execução da atividade, os alunos levaram para os quartos o protótipo de mama, o que chamava a atenção das mães e familiares facilitando a explanação sobre a importância do aleitamento materno, extração manual de leite, pega correta em seio materno, dificuldades e mitos, entre outros assuntos.

0 assunto foi abordado em formato de roda de conversa, ao qual priorizou o conhecimento prévio e cultura das gestantes/puérperas e suas famílias. Houve 6 encontros, com duração de quatro horas cada um, totalizando 28 horas e atendendo aproximadamente 120 famílias. Esta atividade foi realizada nos meses de agosto, setembro e outubro de 2018.

A educação em saúde foi realizada com os alunos da 3 a fase do curso técnico em enfermagem do Instituto Federal de Santa Catarina (Figura 2 e Figura 3). Houve participação de duas docentes, sendo a atividade realizada concomitantemente em dois setores da maternidade.

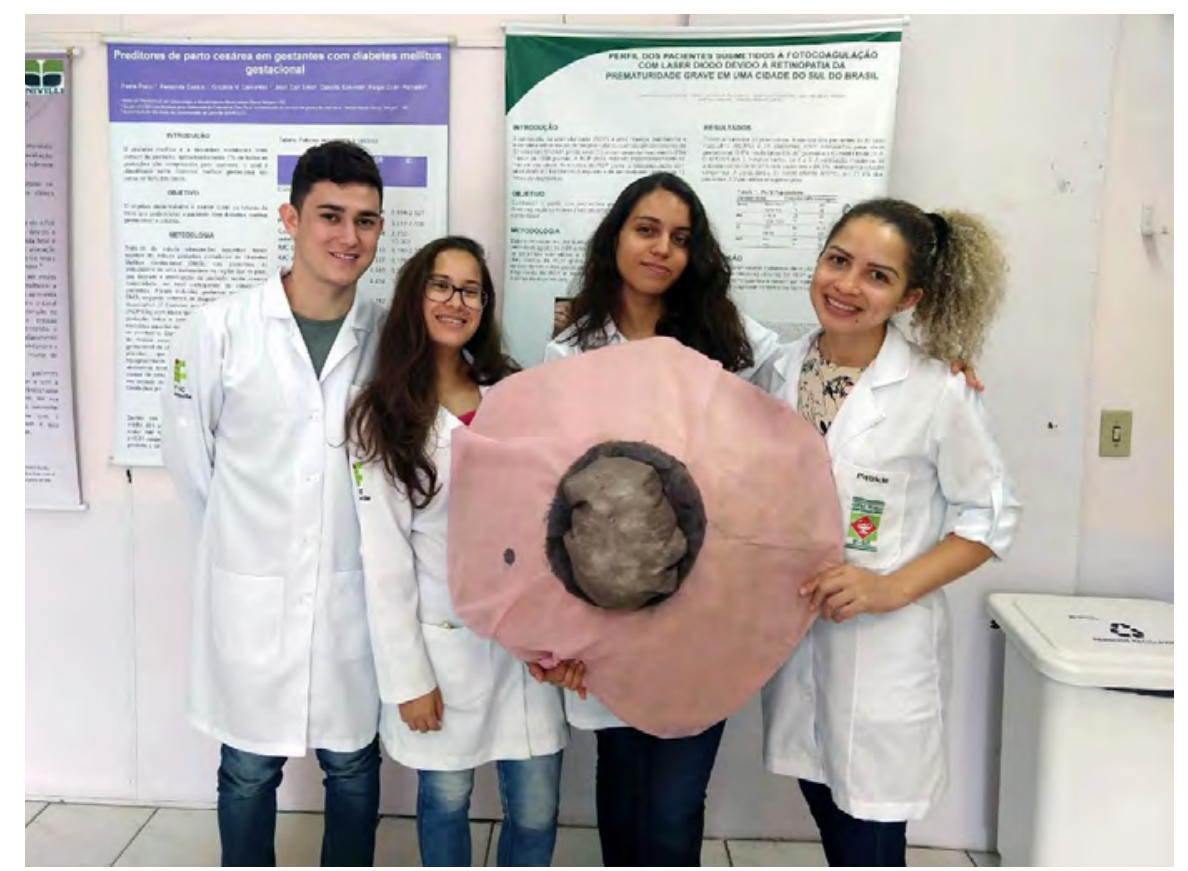

Figura 2: Alunos do curso Técnico em Enfermagem com protótipo que construíram Fonte: Dados desta pesquisa

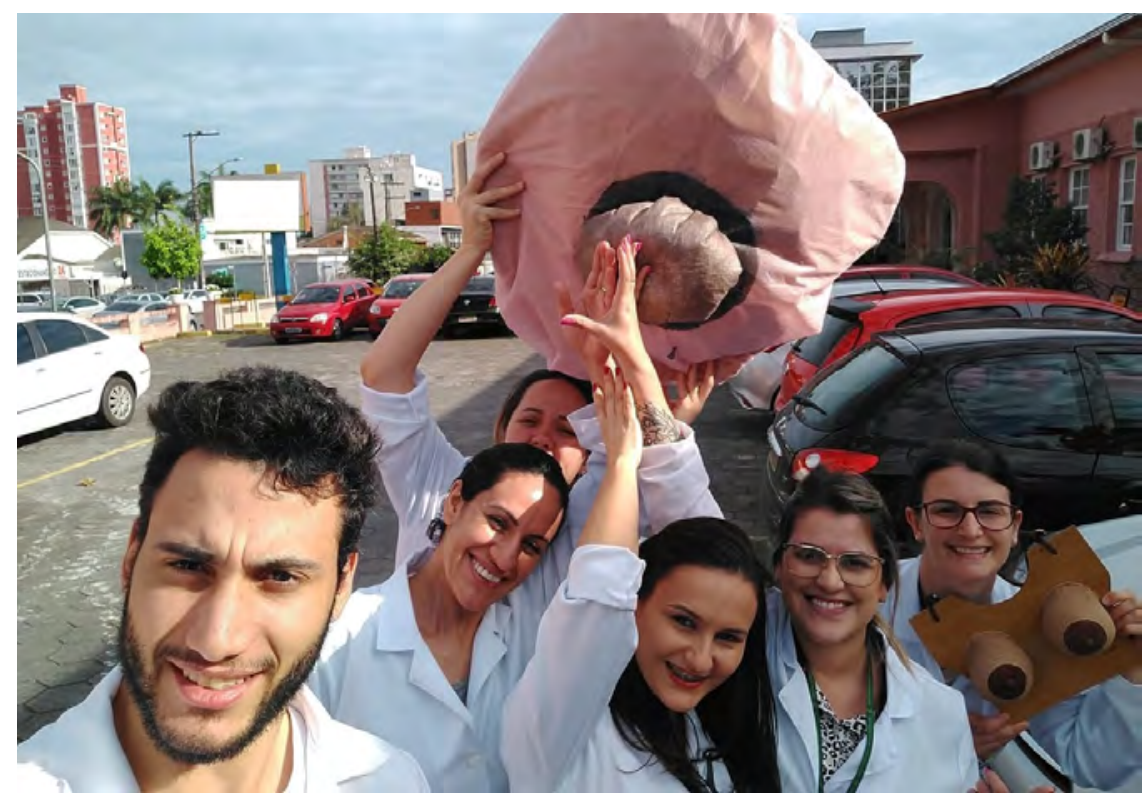

Figura 3: Alunos e Professoras do curso Técnico em Enfermagem Fonte: Dados desta pesquisa 
Os alunos foram organizados em grupos com quatro participantes, onde os mesmos foram até uma maternidade com atendimento exclusivo pelo Sistema Único de Saúde (SUS), no sul do Brasil. A escolha do local deu-se devido à grande quantidade de gestantes/puérperas que chegam até esta instituição e o desconhecimento quanto ao número de puérperas que mantêm o aleitamento materno.

\section{RESULTADOS E DISCUSSÃO}

É no contexto da integração entre instituição de ensino e serviço de saúde que esta atividade acontece. Os quartos onde foram realizadas as atividades possuíam geralmente três gestantes/puérperas. Os alunos, em conjunto com a docente, abordavam as pacientes questionando-as se gostariam de participar da atividade e, a partir de então, iniciava-se a roda de conversa. As perguntas iniciais referiam-se à existência de uma experiência prévia e sua expectativa quanto à continuidade da amamentação.

Esta abordagem, fundamentada no diálogo, é amplamente discutida por Paulo Freire, onde a realidade possa interferir nela mesma, buscando embasamento nas ciências sociais e naturais. Assim, ele vê a educação como um ato político e de conhecimento (FREIRE, 2002). Educar tanto o estudante quanto a família, é um ato que melhora a condição e qualidade de vida dos mesmos.

Para a família, assim como no estudo de Santos, Silva e Silva (2013), esta atividade proporcionou maior motivação e segurança, além da troca de experiências entre estudantes, outras mães e acompanhantes presentes no quarto.

Diversos questionamentos surgiram, principalmente relacionados com mitos, sobre alimentação materna e cólicas do bebê, leite salgado, uso de frutas no mamilo para prevenir fissuras, e outras informações inadequadas, como uso de bico de silicone para proteção do mamilo, água quente para aliviar a dor da mastite ou ingurgitamento, entre outros. Os questionamentos foram principalmente de primíparas.

Construir o conhecimento através de estudos recentes fortaleceu o aprendizado dos alunos, onde a explanação através de linguagem simples envolveu temáticas como: o sabor do leite materno, que altera minimamente de acordo com a dieta da mãe; a orientação de apenas utilizar leite materno para hidratação dos mamilos devido seu alto teor hidratante, sendo contraindicado o uso de frutas ou medicamentos sem prescrição médica; ouso do bico de siliconeapenas em casos de mamilo plano ou invertidoe comindicação de umfonoaudiólogo ou médico; o uso de compressas frias para diminuir a produção de leite materno devido à vasodilatação dos vasos da mama, foram alguns temas recorrentes e plenamente abordados pelos alunos (DEL CASTANHEL, 2016).

As atividades foram realizadas com intervalo de sete dias, proporcionando tempo para que os alunos percebessem sua carência de conhecimento e pesquisassem sobre o assunto para a próxima semana, refletindo de maneira positiva no seu desempenho na próxima intervenção.

Assim como no estudo de Winters et al. (2017), o uso de metodologias ativas auxiliou na construção do conhecimento dos estudantes e das famílias. De início, os alunos demonstraram resistência neste tipo de metodologia, mas ao final da disciplina retornaram com feedback positivo. Nesta perspectiva, o professor deve assumir uma postura de facilitador, tornando o estudante protagonista de sua aprendizagem, preparando-o para situações reais de sua profissão, fazendo com que a educação renove-se, abandonando o antigo conceito de transmissão de informações.

Os estudantes relataram a necessidade de profundo estudo do tema para que pudesse ser discutido com as famílias, e principalmente as mães, que já possuíam conhecimento e experiências prévias à atividade. Essa prática ainda proporcionou a produção de conteúdo, aumentando significativamente a aprendizagem, pois os estudantes assumiram um papel ativo em sua aprendizagem, aumentando a iniciativa, curiosidade científica, criticidade, capacidade de autoavaliação e trabalho em equipe (SOUZA; SILVA; SILVA, 2017).

A alimentação inadequada da criança até os 2 anos de idade está intimamente relacionada à morbimortalidade infantil, o que torna indispensável investir em ações que promovam o aumento da prevalência do aleitamento materno e melhora da qualidade nutricional destas crianças.

\section{CONCLUSÕES}

A experiência de promover a prática do aleitamento materno com os alunos do curso técnico em enfermagem mostrou-se relevante, pois efetivamente contribuiu para o empoderamento das famílias para práticas de aleitamento, desde 0 auto-cuidado até a de seu filho recém-nascido.

Utilizar uma metodologia ativa foi benéfico tanto para as famílias participantes quanto para os alunos. As gestantes/puérperas e familiares tiveram voz, ao relatar suas experiências com aleitamento, suas expectativas e seus medos, tendo um espaço para dialogo e interação. Para os alunos, houve domínio sobre o temaaleitamento materno, sentindo-se seguros para abordar este tema durante a atividade e avaliações posteriores. 
Destaca-se a necessidade da instituição desenvolver ações contínuas de promoção e proteção ao aleitamento materno. Este estudo limitou-se à descrição da atividade proposta, sugerindo um estudo posterior sobre o impacto causado nas famílias e estudantes na utilização desta metodologia.

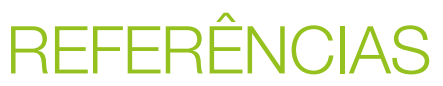

BRASIL. Lei no 11.265, de 3 de janeiro de 2006. Regulamenta a comercialização de alimentos para lactentes e crianças de primeira infância e produtos de puericultura correlatos. Diário Oficial da União, Poder Executivo, Brasília, 2006.

BRASIL. Ministério da Saúde. Agência Nacional de Vigilância de Sanitária. Resolução RDC n 221, de 5 de agosto de 2002. Regulamento técnico sobre chupetas, bicos, mamadeiras e protetores de mamilo. Diário Oficial da União, Poder Executivo, Brasília, DF, 6 ago. 2002.

BRASIL. Ministério da Saúde. Agência Nacional de Vigilância de Sanitária. Resolução RDC n 222, de 5 de agosto de 2002b. Regulamento técnico para promoção comercial dos alimentos para lactentes e crianças de primeira infância. Diário Oficial da União, Poder Executivo, Brasília, DF, 6 ago. 2002.

BRASIL. Ministério da Saúde. Além da sobrevivência: práticas integradas de atenção ao parto, benéficas para a nutrição e a saúde de mães e crianças. Secretaria de Atenção à Saúde, Área Técnica de Saúde da Criança e Aleitamento Materno. 1. ed., 1. reimp. Brasília: Ministério da Saúde, 2013.

BRASIL. Portaria no 1.153, de 22 de maio de 2014. Redefine os critérios de habilitação da Iniciativa Hospital Amigo da Criança (IHAC), como estratégia de promoção, proteção e apoio ao aleitamento materno e à saúde integral da criança e da mulher, no âmbito do Sistema Ǔnico de Saúde (SUS). Brasília: 2014.

\section{BRASIL. Portaria $n^{\circ}$ 2.051/2001. Norma Brasileira de Comercialização de Alimentos para Lactentes e Crianças de Primeira Infância, Bicos, Chupetas e Mamadeiras (NBCAL). Ministério da Saúde, 2001.}

CASTILHO, Silvia Diez; BARROS FILHO, Antônio de Azevedo. Alimentos utilizados ao longo da história para nutrir lactentes. J. Pediatr. (Rio J.), Porto Alegre, v. 86, n. 3, p. 179-188, Jun 2010. Disponível em: http://www.scielo. br/scielo.php?script=sci_arttext\&pid=S0021-75572010000300004\&lng=en\&nrm=iso. Acesso em: 13 ago. 2015.

CAVALCANTE BLL, LIMA UTS. Relato de experiência de uma estudante de Enfermagem em um consultório especializado em tratamento de feridas. J Nurs Health, Pelotas, v. 2, n. 1, p. 94-103, jan./jun. 2012. Disponível em: https://periodicos.ufpel.edu.br/ojs2/index.php/enfermagem/article/view/3447/2832. Acesso em: 21 nov. 2018.

DEL CASTANHEL, M. S. DELZIOVO, C. R. ARAÚJO, L. D. Promoção do leite materno na atenção básica [Recurso eletrônico] / Universidade Federal de Santa Catarina. Florianópolis: UFSC, 2016.

GARCIA, Leila Posenato. The Lancet: série sobre amamentação. Epidemiol. Serv. Saúde, Brasília, v. 25, n. 1, p. 203-204, mar. 2016. Disponível em: http://www.scielo.br/scielo.php?script=sci_arttext\&pid=S223796222016000100203\&lng=en\&nrm=iso. Acesso em: 10 ago. 2018.

FREIRE, P. Pedagogia da Autonomia: saberes necessários à prática educativa. 25. ed. São Paulo: Paz e Terra, 2002.

ORGANIZAÇÃO MUNDIAL DA SAÚDE (OMS). Data Indicators for assessing infant and young child feeding practices: conclusions of a consensus meeting held 6-8 November 2007 in Washington D.C., USA. Disponível em: http://apps.who.int/iris/bitstream/handle/10665/43895/?sequence=1. Acesso em: 22 ago. 2018.

SANTOS, Kelen Crsitna Ramos, SILVA, Marcia Luciane, SILVA, Eveline Franco. Cuidado de Enfermagem na Promoção do Aleitamento Materno em Alojamento Conjunto: um relato de experiência. REAS, vol. 2, n. 1, p. 99-105, 2013. Disponível em: file://C:/Users/1513\%20IRON/Desktop/258-1954-1-PB.pdf. Acesso em: 05 nov. 2018. 
VICTORA, C. G. et al. Association between breastfeeding and intelligence, educational attainment, and income at 30 years of age: a prospective birth cohort study from Brazil. The Lancet, v. 3, n. 4, p. 199-205, 2015. Disponível em: https://www.ncbi.nlm.nih.gov/pmc/articles/PMC4365917/. Acesso em: 12 ago. 2018.

VICTORA C. G. et al. Breastfeeding in the 21st century: epidemiology, mechanisms, and lifelong effect. The Lancet, v. 387, p. 475-90, jan. 2016. Disponível em: https:/www.thelancet.com/journals/lancet/article/ PIIS0140-6736(15)01024-7/fulltext. Acesso em: 28 nov. 2018.

WINTERS, J. R. F. et al. Formação dialógica e participativa na enfermagem: contribuição ao desenvolvimento do pensamento crítico-reflexivo e criativo de acadêmicos. Reme Rev Min Enferm, jan. 2017. Disponível em: file://C:/Users/1513\%20IRON/Downloads/e1067.pdf. Acesso em: 21 nov. 2018. 